\title{
Dexmedetomidine sedation in ICU
}

\author{
Soo-Bong Yu \\ Department of Anesthesiology and Pain Medicine, Kosin University Gospel Hospital, Busan, Korea
}

Dexmedetomidine (DEX), a highly selective $\alpha_{2}$-adrenergic receptor agonist, is the newest agent introduced for sedation in intensive care unit (ICU). The sedation strategy for critically ill patients has stressed light sedation with daily awakening and assessment for neurologic, cognitive, and respiratory functions, since Society of Critical Care Medicine (SCCM) guidelines were presented in 2002. The traditional GABAergic agents, including benzodiazepines and propofol, have some limitations for safe sedatives in this setting, due to an unfavorable pharmacokinetic profile and to detrimental adverse effects (such as lorazepam associated propylene glycol intoxication and propofol infusion syndrome). DEX produces it's sedative, analgesic and cardiovascular effects through $\alpha_{2}$ receptors on the locus ceruleus (LC). Activities of LC, the tuberomammillary nucleus (TMN) are depressed and activity of the ventrolateral preoptic nucleus (VLPO) is increased during DEX sedation, which is similar in features to normal non-REM (NREM) sleep. At the same time, perifornical orexinergic activity is maintained, which might be associated with attention. This mechanism of action produces a normal sleep-like, cooperative sedation. The characteristic feature of sedation, together with a concomitant opioid sparing effect, may decrease the length of time spent on a ventilator, length of stay in ICU, and prevalence and duration of delirium, as the evidence shown from several comparative studies. In addition, DEX has an excellent safety profile. In conclusion, DEX is considered as a promising agent optimized for sedation in ICU. (Korean J Anesthesiol 2012; 62: 405-411)

Key Words: Dexmedetomidine, Delirium, ICU, Sedation, Sleep.

\section{Introduction}

Dexmedetomidine (DEX), the newest sedative, is a highly selective $\alpha_{2}$-adrenergic receptor agonist having different mechanism from traditional agents (benzodiazepine [BDZ], propofol) which act on the GABA receptor. There are subtypes of $\alpha_{2}$-adrenergic receptor, which include $\alpha_{2 \mathrm{~A}}, \alpha_{2 \mathrm{~B}}, \alpha_{2 \mathrm{C}}$; DEX seems to produce its therapeutic effects primarily through the $\alpha_{2 \mathrm{~A}}$ receptor $[1,2]$.

A number of studies have been undertaken to evaluate the efficacy and availability of DEX in various clinical fields including sedation for critically ill patients, adjuvant for general and regional anesthesia, monitored anesthesia care for some invasive procedures, postoperative analgesia, stabilization of heart in cardiac surgery or procedures, since its approval

Received: March 26, 2012. Revised: April 19, 2012. Accepted: April 19, 2012.

Corresponding author: Soo-Bong Yu, M.D., Department of Anesthesiology and Pain Medicine, Kosin University Gospel Hospital, 34, Amnamdong, Seo-gu, Busan 602-702, Korea. Tel: 82-51-990-6283, Fax: 82-51-254-2504, E-mail: sbyu94@hanmail.net

(c) This is an open-access article distributed under the terms of the Creative Commons Attribution Non-Commercial License (http:// creativecommons.org/licenses/by-nc/3.0/), which permits unrestricted non-commercial use, distribution, and reproduction in any medium, provided the original work is properly cited. 
by the FDA in 1999 [3-5]. Among these, especially in the area of sedation in ICU, DEX is expected to play a role in relation to its unique features of action. The sedative strategy for critically ill patients has emphasized light sedation with daily awakening and assessment for neurologic, cognitive, and respiratory functions, since SCCM guidelines were presented in 2002 and concerns on adverse effects associated with oversedation emerged [6-8]. However, traditional sedatives have some limitations as safe drugs for this strategy due to their unfavorable pharmacokinetic [9] or detrimental adverse effects that include lorazepam-associated propylene glycol intoxication [10] and propofol infusion syndrome [11]. Thus, there are growing interests on DEX as a possible alternative.

This paper will review the distinctive pharmacologic features of DEX in regard to the 2002 SCCM guidelines on sedation and analgesia in ICU, which will be reviewed. In addition, its advantages and safety as ideal alternative of current sedatives will be elucidated through literature review.

\section{Summary of 2002 SCCM Guidelines for the Sustained Use of Sedatives and Analgesics in the Critically III Adult [6]}

Analgesia

The level of pain and response to treatment should be assessed regularly and documented systematically by use of an adequate scale.

Fentanyl, hydromorphone, and morphine are the recommended opioids for intravenous use, and scheduled or continuous infusion is preferred over an "as needed" regimen.

Pharmacokinetic characteristics should be considered for selection of drug and regimen.

\section{Sedation}

Sedation of agitated patients should be started only after providing adequate analgesia and treating reversible physiological causes.

A sedation goal should be established and regularly redefined for each patient.

The use of a validated sedation assessment scale (SAS [12], MAAS [13], or VICS [14]) is recommended.

Selection of sedatives should be done considering pharmacokinetic and pharmacodynamic properties among midazolam, diazepam, lorazepam, and propofol.

The titration of the sedative dose to a defined goal is recommended, with systematic tapering of the dose or daily interruption with re-titration to minimize prolonged sedative effects.

The use of sedation guidelines, an algorithm, or a protocol is recommended.

\section{Sedative and analgesic withdrawal}

Doses should be tapered systematically to prevent withdrawal symptoms after high doses or more than approximately seven days of continuous therapy with opioid, BDZ, and propofol.

\section{Delirium}

Routine assessment for the presence of delirium is recommended (The Confusion Assessment Method for the Intensive Care Unit [CAM-ICU] [15] is a promising tool).

Haloperidol is the preferred agent for delirium, and requires electrocardiographic monitoring during its use.

\section{Sleep}

Sleep promotion should include optimization of the environment and nonpharmacologic methods to promote relaxation with adjunctive use of hypnotics.

\section{Characteristic Pharmacology of DEX in the ICU Setting}

The primary site of action in the brain for DEX is the locus ceruleus (LC) [16]. LC plays a key role in regulation of arousal and autonomic activity through numerous projections to multiple sites, including the sleep promoting nucleus and autonomic nucleuses [17]. Inhibition of norepinephrine (NE) release from LC by DEX depresses alertness and sympathetic activity, which present sedation, hypotension (Transient hypertension may develop following high dose of DEX through activation of peripheral vascular $\alpha_{2 \mathrm{~B}}$ receptor.), bradycardia, decreased cardiac output $[16,18]$, and spinal cord mediated analgesia [19].

\section{Analgesic effect}

DEX has both sedative and analgesic effects, unlikely other sedatives. The antinociceptive effect of intrathecal DEX is relatively well described as the previously introduced $\alpha_{2}$ agonist, clonidine [20]. The mechanism of action is considered to be through the $\alpha_{2 \mathrm{~A}}$ and $\alpha_{2 \mathrm{C}}$ receptors on presynaptic C-fiber and postsynaptic spinal dorsal horn neuron $[21,22]$. Intrathecal DEX prolongs duration of motor and sensory blockade by local anesthetics more than twice, and decreases maximum VAS, which effect is stronger than fentanyl [23-25].

In contrast, there is controversy over analgesia with systemic administration. Intravenous DEX prolongs and potentiates local 
anesthetic action that had been administrated intrathecally $[26,27]$; however, it is not evident that DEX has consistent and dose-dependent analgesia against various nociceptive stimuli [19-29]. Rather, DEX has notable effects to increase the potency or reduce requirement of analgesics as an adjunctive. It appears to reduce the requirement for morphine by as much as $66 \%$ after major operations [30-32]. The opioid sparing effect of DEX reduces respiratory depression by opioid, and this could be helpful for patients who breathe spontaneously or are being weaned from a ventilator.

\section{Sedative effect}

DEX induces a unique state called "cooperative sedation". This may be associated with the orexinergic perifornical nucleus activity is maintained with DEX, but not with GABAergic sedatives, which is thought to be connected to attention $[33,34]$. As a result, DEX could enable critically ill patients to do well with daily awakening for assessment of sedation, analgesia, neurologic and respiratory function, which is considered essential to reduce ventilatory support and to improve outcomes.

However, we could find these guidelines are not followed by current ICU care for recent observational studies. In a study which observed 1,381 patients from 44 ICUs, Payen et al. [35] reported that the assessment of sedation (43\%) and analgesia (42\%) was much less than use of sedative $(72 \%)$ and opioids (90\%), and as many as $40-50 \%$ of patients were deeply sedated. Another study, which was conducted in a university associated ICU, revealed that unarousable deep sedation occupied $32 \%$ of total observation, but only $2.6 \%$ of assessment was recorded as oversedation [36]. These results show that many healthcare givers still recognize deep sedation as adequate sedation, and this concept may be associated with that familiar sedative character of frequently used drugs as adequate. In addition, it has been noted that the administration of BDZ leads to more frequent oversedation in ICU [37]. To alter the paradigm of sedation for critically ill patients, an alternative drug with optimized pharmacologic features should be available, as well as changes in the medical staffs' understanding and protocolguided medical practice.

According to several comparative studies, DEX is observed to improve some therapeutic outcomes including the goal of achieved sedation, the duration of ventilatory care, and the length of stay (LOS) in ICU.

\section{Dex vs. Midazolam}

DEX significantly reduced LOS in ICU (45.5 hours vs. 83 hours), duration from stop of drug to discharge from ICU (21 hours vs. 52 hours), and requirement of antihypertensive drug (less than 50\%) with decreased heart rate and mean arterial pressure in 24 hours, in eclampsia patients [38].

The Safety and Efficacy of Dexmedetomidine Compared with Midazolam (SEDCOM) study presents that DEX was associated with shorter median time to extubation by 1.9 days (3.7 days vs. 5.6 days; $\mathrm{P}=0.01$ ) compared to midazolam, but LOS in ICU (5.9 days vs. 7.6 days; $\mathrm{P}=0.24$ ) and time within target Richmond Agitation-Sedation Scale [RASS] [39] score range (77.3\% vs. $75.1 \%$; $=0.18$ ) was similar between 2 drugs [40].

\section{Dex vs. Lorazepam}

The Maximizing Efficacy of Targeted Sedation and Reducing Neurological Dysfunction (MENDS) study resulted in better sedative efficacy (RASS within 1 point of goal $80 \%$ vs. $67 \%$; $\mathrm{P}=$ 0.04 ) with less likelihood of oversedation ( $15 \%$ vs. $33 \%)$ in the DEX group than in the lorazepam group [41].

\section{Dex vs. Propofol}

DEX provided adequate sedation comparable to propofol for postoperative ventilator care of patients with extensive cervical spinal operation [42].

In a study that evaluated sedative efficacy of DEX compared to standard therapy with propofol or midazolam, both drugs showed similar adequacy to light to moderate sedation (RASS 0 to -3 ). However, sedation by DEX was unreliable when deeper sedation (RASS score of -4 or less) is targeted (time at target RASS $42 \%$ vs. $62 \%$; $\mathrm{P}=0.06$ ) [43].

Collectively, though data are not identical with each other, DEX produces better or at least, similar sedative adequacy compared to traditional agents and has potential to decrease the duration of ventilatory care and LOS in ICU. It could provide patients under the risk of hypertensive crisis or tachycardia, with more hemodynamic stability. However, in the case of a required deep level of sedation around a RASS score -4 , DEX might be an inappropriate option, so other agents or use with additive drugs should be considered.

\section{Withdrawal}

Most of studies reported no withdrawal symptoms even following abrupt discontinuation of DEX, but still there was a small possibility of developing agitation, headache, hyperhidrosis, tremor, nausea, vomiting in minor population [40], so a progressive tapering is considered safe.

Unlike clonidine, DEX does not produce rebound hypertension nor tachycardia after prolonged infusion $[44,45]$.

\section{Delirium}

Delirium is an acute neuropsychiatric syndrome of attentional deficit, disorganized thought, cognitive dysfunction with 
fluctuating course and it is reported to affect up to $80 \%$ of patients in ICU [6]. Management of delirium is so important in critical care because it is directly associated with patients outcome. Delirium is now designated for the strongest independent predictor of mortality, duration of ventilatory care, LOS in ICU, and total duration of hospital admission [40,46,47].

The causes that develop or precipitate delirium include sedatives $[47,48]$. The GABAergic agents cause cognitive impairment through direct effect on memory formation and modulation, or indirect sleep disturbance [34]. The normal process of memory involves both slow wave sleep (stage 3,4 of NREM sleep) and REM sleep [49]. BDZ alters sleep architecture and depresses slow wave sleep [50]. On the contrary, DEX has little effect on direct memory impairment [28], and preserves slow wave sleep $[34,51]$. Thus, it has less influence on cognitive dysfunction. This character is accompanied by arousability, facilitates cooperative assessment for delirium and would be advantageous to prevention and diagnosis of delirium.

There is the clinical evidence for DEX's effect on prevention of delirium. Coming 2 studies have high confidence in that daily arousal with assessment for delirium using CAM-ICU once or twice daily was performed to objective patients. SEDCOM study showed lower prevalence of delirium in the DEX group than in the midazolam group (54\% vs. $76.6 \%$; $\mathrm{P}<0.001$ ) [40]. MENDS study measured the number of days alive without delirium or coma, presenting a higher value in the DEX group (7.0 days vs. 3.0 days; $\mathrm{P}=0.01$ ) and lower prevalence of coma as well ( $63 \% \mathrm{vs.}$ $92 \%$; $<0.001)$ than in the lorazepam group [41]. These results show that DEX is superior to BDZ in prevention of delirium or coma.

However, the effect of DEX on delirium, in spite of its favorable pharmacologic distinction with clinical evidence, has not been proven to be significantly different from traditional sedatives in a meta-analysis that included 2,419 patients that participated in 24 trials [52]. This does not mean that DEX has no benefit, considering limitations of significant heterogeneity and inconsistent measurement of delirium between the pooled studies.

DEX seems to have a therapeutic potential on delirium, as well as on prevention. There is an interesting preliminary trial, though it is limited by small sample size, in which 20 patients who could not be weaned from a ventilator because of agitated delirium were treated with DEX or haloperidol [53]. Results showed that the DEX group had a markedly shorter time to extubation (19.9 hours vs. 42.5 hours; $\mathrm{P}=0.016$ ) and ICU LOS (1.5 days vs. 6.5 days; $\mathrm{P}=0.004$ ) as well. Because the duration of ventilatory support and ICU stay are definitely related to a reduction in delirium, particularly in this trial, results reflect the influence of DEX on delirium directly. Considering that haloperidol is preferentially recommended drug for treatment of delirium now, this study has great significance. DEX needs further evaluation with respect to preventive and therapeutic effect on delirium through large, well designed study with definitive measuring protocol and encouraging prospect is expected in this field.

\section{Sleep preserving or mimicking effect}

The sleep deprivation or fragmentation frequently occurring in ICU results in various physiological changes that include immune, metabolic, and endocrine function, all of which precipitate delirium [34,54]. The arousal and sleep is a complicated process that is regulated by the interactions between multiple sites in the brain.

Alertness is increased by the arousal promoting neurotransmitters - NE, serotonin, histamine, acetylcholine, orexin released from activated LC, dorsal raphe nucleus, tuberomammillary nucleus (TMN) acting on the cortex, forebrain, and subcortical area. Meanwhile, sleep is promoted when these activities are reversed by inhibitory action of GABA and galanin from activated ventrolateral preoptic nucleus (VLPO) [55]. During normal NREM sleep, activities of the LC and TMN are depressed and that of VLPO is increased, which is observed similarly in DEX sedation $[33,56]$. But, in sedation with GABAergic agents, increased activity of VLPO depresses TMN, yet spared LC activity is maintained [33]. Accordingly, unchanged noradrenergic activity of LC despite an activated sleep promoting pathway may induce "restless" sleep $[2,56]$. The evidence for DEX's normal sleep preserving effect is supported with electroencephalographic (EEG) finding [51,56]. DEX is definitely more physiologic than other sedatives which inhibit spontaneous sleep, and further investigation should be proceeded to decide what effect this would have on specific therapeutic outcome in the critically ill patient.

\section{Pharmacokinetics, adverse effects and safety}

DEX has an onset of action approximately in 15 minutes after intravenous injection, and reaches its peak concentration after 1 hour of continuous infusion. It has distribution half-life of 6 minutes and terminal elimination half-life of 2 to 2.5 hours. It is usually highly protein-bound, so only $6 \%$ of drug remains free, with relatively large steady state volume of distribution $\left(\mathrm{V}_{\mathrm{dss}}\right.$, $1.33 \mathrm{~L} / \mathrm{kg}$ ). DEX is extensively metabolized through glucuronide conjugation and cytochrome P450 biotransformation in liver with no proven active or toxic metabolites [2]. Clearance may be decreased as much as $50 \%$ with severe hepatic dysfunction. In severe renal disease, pharmacokinetics are usually preserved except for an increase in $\mathrm{V}_{\mathrm{dss}}$, but sedation may be prolonged. To prevent unwanted prolonged sedation, dosage should be 
decreased in patients with hepatic or renal disease, hypoalbuminemia, decreases cardiac output, and elderly patients $[2,57,58]$.

Depressed sympathetic activity with DEX decreases catecholamine in a dose-dependent manner, which subsequently causes a decrease in heart rate and cardiac output. But mean arterial pressure, pulmonary arterial pressure, and vascular resistance show biphasic response of initial decrease and later increase with dose-escalation. Stroke volume is well preserved until the DEX concentration is high, but cardiac output declines due to bradycardia [28]. This cardiovascular effect following DEX treatment would prevent hypertension and tachycardia or decrease requirements for antihypertensives [38,40]. However, it might be harmful to hemodynamically unstable patients.

Most studies consistently pointed out bradycardia as the only adverse effect of DEX. Actually, DEX does not increase the risk of bradycardia in general, but only in cases with both a loading dose and high maintenance dose $(>0.7 \mu \mathrm{g} / \mathrm{kg} / \mathrm{h})$ are administrated, and furthermore, it does not seem to be associated with increased risk of significant hypotension requiring treatment [52]. Even if bradycardia has developed, it is reversed with relatively simple intervention, such as by decreasing the dose [40]. More seriously, asystole has developed in some cases, mostly when concomitant sympathetic inhibitors or cholinergic drugs are given for surgery or procedure, particularly with vagal nervous stimulation (eg, sternal separation, colonoscopy) applied, and in most cases, normal sinus rhythm is restored with discontinuation of DEX [59-61].

The recommended dose for sedation in ICU, is a loading dose of $1 \mu \mathrm{g} / \mathrm{kg}$ over 10 minutes followed by continuous infusion of $0.2-0.7 \mu \mathrm{g} / \mathrm{kg} / \mathrm{h}(<24 \mathrm{~h})$. However, several trials have used a higher dose up to $1.5 \mu \mathrm{g} / \mathrm{kg} / \mathrm{h}$ over 24 hours, without clinically significant problems $[40,41,43-45]$. Actually, DEX has excellent safety considering there were no adverse effects, except for oversedation in the cases of accidentally overdose of 2.5 to 60 times of intended dosages [62].

However, there still is a long way to go to extend all the benefits of DEX to the general population of critically ill patients. Several studies have limitations of that exclude many disease groups - neurologic disease, acute MI, heart block, trauma, burn injury, serious CNS pathology, severe liver disease, pregnancy from clinical trials or small sample size or being unblinded [45].

\section{Conclusion}

DEX preserves a natural sleep pattern and induces cooperative sedation in which patients are easily arousable, leads to less impairment in cognitive function, and has an opioid sparing effect as well. If daily arousal and appropriate assessment for sedation and delirium are performed routinely, DEX decreases duration of ventilatory care, ICU stay, prevalence, and duration of delirium with better adequacy of sedation, and therefore improvement in outcomes. DEX is a promising sedative optimized for ICU care.

\section{References}

1. Berkowitz DE, Price DT, Bello EA, Page SO, Schwinn DA. Localization of messenger RNA for three distinct alpha 2-adrenergic receptor subtypes in human tissues. Evidence for species heterogeneity and implications for human pharmacology. Anesthesiology 1994; 81: 1235-44.

2. Panzer O, Moitra V, Sladen RN. Pharmacology of sedative-analgesic agents: dexmedetomidine, remifentanil, ketamine, volatile anesthetics, and the role of peripheral $\mathrm{Mu}$ antagonists. Anesthesiol Clin 2011; 29: 587-605.

3. Mantz J, Josserand J, Hamada S. Dexmedetomidine: new insights. Eur J Anaesthesiol 2011; 28: 3-6.

4. Na HS, Song IA, Park HS, Hwang JW, Do SH, Kim CS. Dexmedetomidine is effective for monitored anesthesia care in outpatients undergoing cataract surgery. Korean J Anesthesiol 2011; 61: 453-9.

5. Chrysostomou C, Beerman L, Shiderly D, Berry D, Morell VO, Munoz R. Dexmedetomidine: a novel drug for the treatment of atrial and junctional tachyarrhythmias during the perioperative period for congenital cardiac surgery: a preliminary study. Anesth Analg 2008; 107: 1514-22.

6. Jacobi J, Fraser GL, Coursin DB, Riker RR, Fontaine D, Wittbrodt ET, et al. Clinical practice guidelines for the sustained use of sedatives and analgesics in the critically ill adult. Crit Care Med 2002; 30: 11941.

7. Treggiari MM, Romand JA, Yanez ND, Deem SA, Goldberg J, Hudson $\mathrm{L}$, et al. Randomized trial of light versus deep sedation on mental health after critical illness. Crit Care Med 2009; 37: 2527-34.

8. Riker RR, Fraser GL. Altering intensive care sedation paradigms to improve patient outcomes. Anesthesiol Clin 2011; 29: 663-74.

9. Spina SP, Ensom MH. Clinical pharmacokinetic monitoring of midazolam in critically ill patients. Pharmacotherapy 2007; 27 : 38998.

10. Nelsen JL, Haas CE, Habtemariam B, Kaufman DC, Partridge A, Welle $S$, et al. A prospective evaluation of propylene glycol clearance and accumulation during continuous-infusion lorazepam in critically ill patients. J Intensive Care Med 2008; 23: 184-94.

11. Riker RR, Glisic EK, Fraser GL. Propofol infusion syndrome: difficult to recognize, difficult to study. Crit Care Med 2009; 37: 3169-70.

12. Riker RR, Picard JT, Fraser GL. Prospective evaluation of the Sedation-Agitation Scale for adult critically ill patients. Crit Care Med 1999; 27: 1325-9.

13. Devlin JW, Boleski G, Mlynarek M, Nerenz DR, Peterson E, Jankowski M, et al. Motor Activity Assessment Scale: a valid and reliable sedation scale for use with mechanically ventilated patients in an adult surgical intensive care unit. Crit Care Med 1999; 27: $1271-5$.

14. de Lemos J, Tweeddale M, Chittock D. Measuring quality of sedation in adult mechanically ventilated critically ill patients. the Vancouver Interaction and Calmness Scale. Sedation Focus Group. 
J Clin Epidemiol 2000; 53: 908-19.

15. Ely EW, Margolin R, Francis J, May L, Truman B, Dittus R, et al. Evaluation of delirium in critically ill patients: validation of the Confusion Assessment Method for the Intensive Care Unit (CAMICU). Crit Care Med 2001; 29: 1370-9.

16. Correa-Sales C, Rabin BC, Maze M. A hypnotic response to dexmedetomidine, an alpha 2 agonist, is mediated in the locus coeruleus in rats. Anesthesiology 1992; 76: 948-52.

17. Samuels ER, Szabadi E. Functional neuroanatomy of the noradrenergic locus coeruleus: its roles in the regulation of arousal and autonomic function part I: principles of functional organisation. Curr Neuropharmacol 2008; 6: 235-53.

18. Nelson LE, Lu J, Guo T, Saper CB, Franks NP, Maze M. The alpha2adrenoceptor agonist dexmedetomidine converges on an endogenous sleep-promoting pathway to exert its sedative effects. Anesthesiology 2003; 98: 428-36.

19. Guo TZ, Jiang JY, Buttermann AE, Maze M. Dexmedetomidine injection into the locus ceruleus produces antinociception. Anesthesiology 1996; 84: 873-81.

20. Schug SA, Saunders D, Kurowski I, Paech MJ. Neuraxial drug administration: a review of treatment options for anaesthesia and analgesia. CNS Drugs 2006; 20: 917-33.

21. Yoshitomi T, Kohjitani A, Maeda S, Higuchi H, Shimada M, Miyawaki T. Dexmedetomidine enhances the local anesthetic action of lidocaine via an alpha-2A adrenoceptor. Anesth Analg 2008; 107: 96101.

22. Ishii H, Kohno T, Yamakura T, Ikoma M, Baba H. Action of dexmedetomidine on the substantia gelatinosa neurons of the rat spinal cord. Eur J Neurosci 2008; 27: 3182-90.

23. Gupta R, Bogra J, Verma R, Kohli M, Kushwaha JK, Kumar S. Dexmedetomidine as an intrathecal adjuvant for postoperative analgesia. Indian J Anaesth 2011; 55: 347-51.

24. Gupta R, Verma R, Bogra J, Kohli M, Raman R, Kushwaha JK. A Comparative study of intrathecal dexmedetomidine and fentanyl as adjuvants to Bupivacaine. J Anaesthesiol Clin Pharmacol 2011; 27: $339-43$.

25. Kamibayashi T, Maze M. Clinical uses of alpha2-adrenergic agonists. Anesthesiology 2000; 93: 1345-9.

26. Al-Mustafa MM, Badran IZ, Abu-Ali HM, Al-Barazangi BA, Massad IM, Al-Ghanem SM. Intravenous dexmedetomidine prolongs bupivacaine spinal analgesia. Middle East J Anesthesiol 2009; 20: 22531.

27. Hong JY, Kim WO, Yoon Y, Choi Y, Kim SH, Kil HK. Effects of intravenous dexmedetomidine on low-dose bupivacaine spinal anaesthesia in elderly patients. Acta Anaesthesiol Scand 2012; 56: 382-7.

28. Ebert TJ, Hall JE, Barney JA, Uhrich TD, Colinco MD. The effects of increasing plasma concentrations of dexmedetomidine in humans. Anesthesiology 2000; 93: 382-94.

29. Angst MS, Ramaswamy B, Davies MF, Maze M. Comparative analgesic and mental effects of increasing plasma concentrations of dexmedetomidine and alfentanil in humans. Anesthesiology 2004; 101: 744-52.

30. Ohtani N, Yasui Y, Watanabe D, Kitamura M, Shoji K, Masaki E. Perioperative infusion of dexmedetomidine at a high dose reduces postoperative analgesic requirements: a randomized control trial. J Anesth 2011; 25: 872-8.
31. Arain SR, Ruehlow RM, Uhrich TD, Ebert TJ. The efficacy of dexmedetomidine versus morphine for postoperative analgesia after major inpatient surgery. Anesth Analg 2004; 98: 153-8.

32. Guneli E, Karabay Yavasoglu NU, Apaydin S, Uyar M, Uyar M. Analysis of the antinociceptive effect of systemic administration of tramadol and dexmedetomidine combination on rat models of acute and neuropathic pain. Pharmacol Biochem Behav 2007; 88: 9-17.

33. Coull JT, Jones ME, Egan TD, Frith CD, Maze M. Attentional effects of noradrenaline vary with arousal level: selective activation of thalamic pulvinar in humans. Neuroimage 2004; 22: 315-22.

34. Sanders RD, Maze M. Contribution of sedative-hypnotic agents to delirium via modulation of the sleep pathway. Can J Anaesth 2011; 58: 149-56.

35. Payen JF, Chanques G, Mantz J, Hercule C, Auriant I, Leguillou JL, et al. Current practices in sedation and analgesia for mechanically ventilated critically ill patients: a prospective multicenter patientbased study. Anesthesiology 2007; 106: 687-95.

36. Weinert CR, Calvin AD. Epidemiology of sedation and sedation adequacy for mechanically ventilated patients in a medical and surgical intensive care unit. Crit Care Med 2007; 35: 393-401.

37. Devlin JW. The pharmacology of oversedation in mechanically ventilated adults. Curr Opin Crit Care 2008; 14: 403-7.

38. Esmaoglu A, Ulgey A, Akin A, Boyaci A. Comparison between dexmedetomidine and midazolam for sedation of eclampsia patients in the intensive care unit. J Crit Care 2009; 24: 551-5.

39. Sessler CN, Gosnell MS, Grap MJ, Brophy GM, O'Neal PV, Keane KA, et al. The Richmond Agitation-Sedation Scale: validity and reliability in adult intensive care unit patients. Am J Respir Crit Care Med 2002; 166: 1338-44.

40. Riker RR, Shehabi Y, Bokesch PM, Ceraso D, Wisemandle W, Koura F, et al Dexmedetomidine vs midazolam for sedation of critically ill patients: a randomized trial. JAMA 2009; 301: 489-99.

41. Pandharipande PP, Pun BT, Herr DL, Maze M, Girard TD, Miller $\mathrm{RR}$, et al. Effect of sedation with dexmedetomidine vs lorazepam on acute brain dysfunction in mechanically ventilated patients: the MENDS randomized controlled trial. JAMA 2007; 298: 2644-53.

42. Terao Y, Ichinomiya T, Higashijima U, Tanise T, Miura K, Fukusaki $\mathrm{M}$, et al. Comparison between propofol and dexmedetomidine in postoperative sedation after extensive cervical spine surgery. J Anesth 2012; 26: 179-86.

43. Ruokonen E, Parviainen I, Jakob SM, Nunes S, Kaukonen M, Shepherd ST, et al. Dexmedetomidine versus propofol/midazolam for long-term sedation during mechanical ventilation. Intensive Care Med 2009; 35: 282-90.

44. Gerlach AT, Murphy CV, Dasta JF. An updated focused review of dexmedetomidine in adults. Ann Pharmacother 2009; 43: 2064-74.

45. Guinter JR, Kristeller JL. Prolonged infusions of dexmedetomidine in critically ill patients. Am J Health Syst Pharm 2010; 67: 1246-53.

46. Ely EW, Shintani A, Truman B, Speroff T, Gordon SM, Harrell FE Jr, et al. Delirium as a predictor of mortality in mechanically ventilated patients in the intensive care unit. JAMA 2004; 291: 1753-62.

47. Frontera JA. Delirium and sedation in the ICU. Neurocrit Care 2011; 14: 463-74.

48. Pandharipande P, Shintani A, Peterson J, Pun BT, Wilkinson GR, Dittus RS, et al. Lorazepam is an independent risk factor for trans- 
itioning to delirium in intensive care unit patients. Anesthesiology 2006; 104: 21-6.

49. Walker MP, Stickgold R. Sleep-dependent learning and memory consolidation. Neuron 2004; 44: 121-33.

50. Borbély AA, Achermann P. Ultradian dynamics of sleep after a single dose of benzodiazepine hypnotics. Eur J Pharmacol 1991; 195: 11-8.

51. Huupponen E, Maksimow A, Lapinlampi P, Särkelä M, Saastamoinen A, Snapir A, et al. Electroencephalogram spindle activity during dexmedetomidine sedation and physiological sleep. Acta Anaesthesiol Scand 2008; 52: 289-94.

52. Tan JA, Ho KM. Use of dexmedetomidine as a sedative and analgesic agent in critically ill adult patients: a meta-analysis. Intensive Care Med 2010; 36: 926-39.

53. Reade MC, O'Sullivan K, Bates S, Goldsmith D, Ainslie WR, Bellomo R. Dexmedetomidine vs. haloperidol in delirious, agitated, intubated patients: a randomised open-label trial. Crit Care 2009; 13: R75.

54. Salas RE, Gamaldo CE. Adverse effects of sleep deprivation in the ICU. Crit Care Clin 2008; 24: 461-76.

55. Nelson LE, Guo TZ, Lu J, Saper CB, Franks NP, Maze M. The sedative component of anesthesia is mediated by GABA(A) receptors in an endogenous sleep pathway. Nat Neurosci 2002; 5: 979-84.
56. Mason KP, O'Mahony E, Zurakowski D, Libenson MH. Effects of dexmedetomidine sedation on the EEG in children. Paediatr Anaesth 2009; 19: 1175-83.

57. Venn RM, Karol MD, Grounds RM. Pharmacokinetics of dexmedetomidine infusions for sedation of postoperative patients requiring intensive caret. Br J Anaesth 2002; 88: 669-75.

58. Iirola T, Ihmsen H, Laitio R, Kentala E, Aantaa R, Kurvinen JP, et al. Population pharmacokinetics of dexmedetomidine during longterm sedation in intensive care patients. Br J Anaesth 2012; 108: 460-8.

59. Zhang X, Schmidt U, Wain JC, Bigatello L. Bradycardia leading to asystole during dexmedetomidine infusion in an 18 year-old double-lung transplant recipient. J Clin Anesth 2010; 22: 45-9.

60. Ingersoll-Weng E, Manecke GR Jr, Thistlethwaite PA. Dexmedetomidine and cardiac arrest. Anesthesiology 2004; 100: 738-9.

61. Jalowiecki P, Rudner R, Gonciarz M, Kawecki P, Petelenz M, Dziurdzik P. Sole use of dexmedetomidine has limited utility for conscious sedation during outpatient colonoscopy. Anesthesiology 2005; 103: 269-73.

62. Jorden VS, Pousman RM, Sanford MM, Thorborg PA, Hutchens MP. Dexmedetomidine overdose in the perioperative setting. Ann Pharmacother 2004; 38: 803-7. 